\title{
Nutritional complications and its effects on human health.
}

\section{Alamgir Khan ${ }^{1 *}$, Sami Ullah Khan ${ }^{1}$, Salahuddin Khan ${ }^{1}$, Syed zia-ul-islam ${ }^{1}$, Naimatullah Khan Baber ${ }^{2}$, Manzoor Khan ${ }^{3}$}

${ }^{1}$ Department of Sports Science \& Physical Education, Gomal University, Khyber Pakhtunkhwa, Pakistan

${ }^{2}$ Department of Agriculture, Gomal University, Khyber Pakhtunkhwa, Pakistan

${ }^{3}$ Hazara University Manshera, Khyber Pakhtoonkhwa, Pakistan

\begin{abstract}
The present review study was an attempt to investigate the perceptions of worldwide researcher about nutritional complication and its effects on health. In this regard, 20 research articles were included in the study. Focusing on nutritional complication and its effects on health, the findings of 10 research articles were carefully reviewed and then it is concluded that improper intake in both form under nutrition and over-nutrition have adverse effects on health.
\end{abstract}

Keywords: Nutritional, Complications, Human health

Accepted on January 26, 2018

\section{Introduction}

Nutrition is the quantity and quality of food that the body receives. The body breaks down the food to get the molecules that it actually needs: proteins, fats, carbohydrates, vitamins, and minerals. Nutrition refers to sum of all processes involved in how organisms obtain nutrients, metabolize them, and use them to support all of life's processes [1]. If body does not have these things, than the body will unable to work properly. And the possessions of bad nutrition can be terrible.

Nutrition has been one of the basic needs of every individual living on the earth. Nutrition is that process which provides energy to the body to perform various tasks in routine life. Different kinds of disease, weakness and disabilities are closely related with the intake of insufficient amount to food nutrients. This study focus upon nutritional complications and its effects on human health. The research study conducted under the title "Nutritional complications and its effects on human health. All possible efforts were made to reach at certain findings and conclusions of the study.

\section{Objectives of the Study}

1. To assess the nutrition complication and its effect on human health.

2. To investigate the causative factors of nutrition complication.

3. To assess the relationship of nutrition complication and its effect on human health.

As this study was related with nutritional complications and its effects on health. Similarly systematic reviews of 20 articles were drawn for the purpose to extract the findings and conclusion of the study. At the end of the study 10 research articles were included. The inclusion and exclusion criteria were:

\section{Inclusion criteria}

- Research articles published from 2010 to 2016 were included in the study.

- The articles having data base of PubMed, Google scholar were included in the study.

\section{Exclusion criteria}

- The articles having no indexation with PubMed and Google scholar were excluded from the study.

- The articles published before 2010 were excluded from the study.

\section{Review}

According to World Health Organization (WHO) Nutrition is a fundamental pillar of human life, health and development across the entire life span. From the earliest stages of fetus development, at the time of birth, through infancy, childhood, adolescence and old age. Proper food and good nutrition are essential for survival, physical growth, mental development, performance and productivity, health and well-being. It is an essential foundation for human development. Healthy eating in childhood and adolescence is important for proper growth and development and to prevent various health conditions. Nutrition also indirectly impacts Academics performance [2].

The proper amount of food plays a vital role in the complete health of an individual. The food which we provide to the body is having more nutrient content. The food contains energy, protein, essential fats, vitamins and minerals to live, grow and function properly. We need a wide variety of different foods to provide the right amounts of nutrients for good health. Enjoyment of a healthy diet can also be one of the great cultural pleasures of life. The foods and dietary patterns that promote good nutrition are outlined in the Infant Feeding Guidelines and Australian Dietary Guidelines. An unhealthy diet increases the risk of many diet-related diseases [3].

The fundamental world health organization (WHO) goal of health for all means that people everywhere, throughout their lives, have the opportunity to reach and maintain the highest attainable level of health. This is impossible in the presence of hunger, starvation, and malnutrition. Basic nutrients, such as carbohydrates, fats, and proteins, are the basis of all life activities. These constitute the carbon skeleton of numerous useful molecules, and deliver energy through oxidative decomposition. Traditionally, the main aim of nutrition is 
to prevent and treat nutritional deficiencies. However, when nutrition is adequate or excessive, the body faces the problems of quantitative control of the nutrients absorption and storage,

The Study revealed that the prime cause of malnutrition in developed countries is disease, hence the expression "diseaserelated malnutrition". Pakistan is one among the developing countries of the world. Just like other developing countries, the people of Pakistan facing so many health problems due to poor or insufficient intake or unavailability of nutrition. According to National Health Services Directory (NHSD) human body need to utilize sufficient amount of food on daily basis [4,5]. Poor eating habits such as insufficient intake or high intake both have adverse effects on health. These problems include obesity, high blood pressure, high cholesterol, heart disease and stroke, type-2 diabetes, osteoporosis and so on. Poor nutrition leads an individual to illness or lead to headaches and stomachaches [6].

Poor intake of nutrition is a part of one behavior. "Poor nutritional and dietary habits affect how you feel, look, think and act. A bad diet results in lower core strength, slower problem solving ability and muscle response time, and less alertness"[7]. The author further stated that poor nutrition adversely effect on health. Poor nutrition early in life can impair neural development, leading to lower IQ in humans being.

Development and growth of the body directly concerned with nutrition and diet use by a person on daily basis. Use of balance diet helps one to stay healthy and to perform the social activities in beneficial manner. Lack of balance diet has adverse effect on overall structural and functional capacity of then body [8].

According to UNICEF poor nutritional habits may cause many health problems such as weakens of immune system, severity of illness and impeding recovery. It means that use of little or high amount of nutrition may cause the failure of various body mechanisms. Malnutrition commonly affects all groups in a community, but infants and young children are the most vulnerable because of their high nutritional requirements for growth and development. Another group of concern is pregnant women, given that a malnourished mother is at high risk of giving birth to a LBW baby who will be prone to growth failure during infancy and early childhood, and be at increased risk of morbidity and early death [9]. Malnourished girls, in particular, risk becoming yet another malnourished mother, thus contributing to the intergenerational cycle of malnutrition. Malnutrition is related to a decline in general functional status and to decreased bone mass, immune dysfunction, delayed postsurgery recovery, high hospitalization and readmission rates, and increased mortality [10]. Obesity is a serious health problems and a very huge number of people in now-e-days are facing the problem of obesity. There are so many factors responsible for this problems but the over nutrition is the one among the main factors caused obesity among the masses [11]. Obesity is fast growing problem throughout the world. Obesity may cause of Type II diabetes because it causes insulin resistance and is associated with physical inactivity. A person become obese when he get too much energy and not utilize it properly (World Health Organization) Diabetes mellitus (DM) is a series of a metabolic disorder associated with high glucose level due to either defect in insulin secretion, insulin action or both [12].
The major causes of death, illness and disability in which diet and nutrition play an important role include coronary heart disease, stroke, hypertension, atherosclerosis, obesity, some forms of cancer, Type 2 diabetes, osteoporosis, dental caries, gall bladder disease, dementia and nutritional anemia's. The Infant Feeding Guidelines and Australian Dietary Guidelines assist us to eat a healthy diet and help minimize our risk of developing diet-related diseases [13]. The author stated that health expert always recommends diets for the well maintenance of health. Lack of sufficient intake of diet adversely affects the functional capacity of the body [14]. Balance or healthy diet refers to the diet maintain and promote health It estimated that $80 \%$ of all cardiovascular disease, $90 \%$ of all type 2 diabetes and $30 \%$ of all cancer could be prevented by eating a healthy diet, increasing physical activity and avoiding smoking [15]. In contrast, nutritional deficiencies (particularly zinc, B vitamins, Omega-3 fatty acids, and protein) early in life can affect the cognitive development of children [16].

According to Australian Bureau of Statistics (2014) diet and exercise both are necessary for controlling the weight of the body [17]. For reducing body weight one need to eat according to need of the body, Eat according to the nature of activity and Perform regular exercise. Human body need to utilize sufficient intake of food on daily basis. Many people may leads to weakness or obesity due to unawareness about the daily intake of nutrition. Therefore, it is necessary to have awareness about the daily intake of food [18].

\section{Presentation and Analysis of the Previous Research Studies}

Table 1 shows the findings of the previous research studies.

\section{Discussion}

\section{Based on analysis, the researcher draws the following findings}

- Lacking of sufficient intake of food may cause of weakness.

- Over intake of food may cause obesity.

- Exercise is the basic tool for promoting health.

It is found by the present research study that lacking of sufficient intake of food may cause of weakness. This emerging concept is supported by the study conducted by different Researchers by indicating that insufficient intake of food may lead the body toward weakness. The findings of the study conducted also inline of the present study because they concluded that insufficient intake of nutrition may cause weakness and improper growth of the body [14].

The findings of the present study depicted that over intake of food may cause obesity. The study conducted to find out that high intake of food ingredients may cause rise in fats in the body. Same findings is drawn by the study conducted indicating that use or high intake of food may cause obesity among the child's as well as among the adults.

The present study showed that exercise is the basic tool for promoting health and reducing health complications. The 
Table 1. Showing the findings of the previous research studies.

\begin{tabular}{|c|c|}
\hline Authors Study (Reference No.) & Findings of the study \\
\hline $\begin{array}{l}\text { National Health Services Directory } \\
(\text { NHSD) (2015) }[5]\end{array}$ & $\begin{array}{l}\text { Human body need to utilize sufficient amount of food on daily basis. Poor eating habits such as insufficient intake or high intake } \\
\text { both have adverse effects on health. }\end{array}$ \\
\hline Ripha Ajmera [7] & $\begin{array}{l}\text { Poor nutritional and dietary habits affect how you feel, look, think and act. A bad diet results in lower core strength, slower } \\
\text { problem solving ability and muscle response time, and less alertness }\end{array}$ \\
\hline Sturm [11] & $\begin{array}{l}\text { There are so many factors responsible for this problems but the over nutrition is the one among the main factors caused obesity } \\
\text { among the masses }\end{array}$ \\
\hline Tuomilehto et al. [12] & $\begin{array}{l}\text { Diabetes mellitus (DM) is a series of a metabolic disorder associated with high glucose level due to either defect in insulin } \\
\text { secretion, insulin action or both }\end{array}$ \\
\hline $\begin{array}{l}\text { Department of Health and Ageing, } \\
\text { National Health and Medical Research } \\
\text { Council [13] }\end{array}$ & \\
\hline Mann et al. [14] & $\begin{array}{l}\text { Balance diet play vital role in maintenance of health. Lack of sufficient intake of diet adversely affects the functional capacity } \\
\text { of the body. }\end{array}$ \\
\hline $\begin{array}{l}\text { According Australian Bureau of Statistics } \\
\text { [17] }\end{array}$ & Diet and exercise both are necessary for controlling the weight of the body. \\
\hline Ahmed et al. [19] & $\begin{array}{l}\text { Malnutrition is related to a decline in general functional status and to decreased bone mass, immune dysfunction, delayed post- } \\
\text { surgery recovery, high hospitalization and readmission rates, and increased mortality }\end{array}$ \\
\hline
\end{tabular}

exercise is the basic tool for promoting health and reducing the chances of obesity among the child's. This finding also supported the findings stated above. The findings of the study supported the present study findings because they concluded that for the wellbeing of health exercise is considered necessary

Based on previous literature the researcher found that:

1. Lacking of sufficient intake of food may cause of weakness.

2. Over intake of food may cause obesity.

3. Exercise is the basic tool for promoting health and reducing health complications.

\section{Conclusion}

Based on findings of the previous research study the researcher concluded that human health need to utilize sufficient nutrition on daily basis. The findings of previous research also both form of malnutrition (Under nutrition and over nutrition) adversely affect the health.

\section{Recommendations of the Study}

Based on findings and conclusion the researcher recommended that:

1. Good health experts discuss eating and drinking with the patient and provide advice regarding healthy food choices for the purpose to make sure the patient is receiving a healthy, nutritious diet.

2. People may be made aware about the sufficient daily intake of nutrition by conducting different awareness programs.

3. Set a pattern of frequent meals and snacks during the day rather than simply trying to eat more at meals.

4. Sufficient diet may be given to children for promoting their health.

5. Safe and hygienic food may be taken for the purpose to avoid health problems.

6. Diet may be given to the children according to the daily need of their bodies.

\section{References}

1. Lawrence TLJ, Pearce J. Some effects of wintering yearling beef cattle on different planes of nutrition: I. Live-weight gain, food consumption and body measurement changes during the winter period and the subsequent grazing period. J Agric Sci. 1964;63(1):5-21.

2. Popkin BM, Adair LS, Ng SW. Global nutrition transition and the pandemic of obesity in developing countries. Nutr Rev. 2012;70(1):3-21.

3. Ensminger ME, Ensminger AH. Foods \& Nutrition Encyclopedia. CRC press, US. 1993.

4. Stratton RJ, Green CJ, Elia M. Disease-related malnutrition: an evidence-based approach to treatment. CABI, Wallingford. 2003.

5. National Health Services Directory (NHSD). The risks of poor nutrition. 2015.

6. Brown JL, Beardslee WH, Prothrow-Stith D. Impact of school breakfast on children's health and learning: An analysis of the scientific research. 2008

7. Ajmera R. The effects of poor nutrition on your health. Livestrong.Com. 2017.

8. Bruch H. Eating disorders: Obesity, anorexia nervosa, and the person within. Basic Books, New York. 1973:396.

9. UNICEF. What is the role of nutrition? UNICEF. 2012.

10. Ahmed T, Haboubi N. Assessment and management of nutrition in older people and its importance to health. Clin Interv Aging. 2010;5:207-216.

11. Sturm R. Increases in morbid obesity in the USA: 2000 2005. Public health. 2007;121(7):492-496.

12. Tuomilehto J, Lindstrom J, Eriksson JG, et al. Prevention of type 2 diabetes mellitus by changes in lifestyle among subjects with impaired glucose tolerance. N Engl J Med. 2001;344(18):1343-1350.

13. https://www.nhmrc.gov.au/guidelines-publications/n55 
14. Mann T, Tomiyama AJ, Westling E, et al. Medicare's search for effective obesity treatments: diets are not the answer. Am Psychol. 2007;62:220-233

15. World Health Organization. Nutrition for health and development: a global agenda for combating malnutrition. WHO, Geneva. 2000.

16. Sorhaindo A, Feinstein L. What is the relationship between child nutrition and school outcomes? Centre for Research on the Wider Benefits of Learning Institute of Education, London. 2006.

17. http://www.abs.gov.au/ausstats/abs@.nsf/Lookup/4364.0.5 5.007main+features $12011-12$

18. Arvanitoyannis IS, Van Houwelingen-Koukaliaroglou M. Functional foods: a survey of health claims, pros and cons, and current legislation. Crit Rev Food Sci Nutr. 2005;45(5):385-404.

\section{*Correspondence to:}

Alamgir Khan

Department of Sports Science \& Physical Education

Gomal University

Khyber Pakhtunkhwa,

Pakistan

Tel: 03329741015

E-mail: alamgir1989@hotmail.com 